\title{
Angina Severity at the Time of Revascularization in Patients With Diabetes Mellitus and Its Association With Long-term Outcomes: A Multicenter Cohort Study.
}

\author{
Nozomi Niimi

\section{Satoshi Shoji} \\ Keio University Hospital: Keio Gijuku Daigaku Byoin

\section{Mitsuaki Sawano} \\ Keio University Hospital: Keio Gijuku Daigaku Byoin \\ Nobuhiro Ikemura \\ Keio University Hospital: Keio Gijuku Daigaku Byoin

\section{Yasuyuki Shiraishi} \\ Keio University Hospital: Keio Gijuku Daigaku Byoin

\section{Taku Inohara} \\ Keio University Hospital: Keio Gijuku Daigaku Byoin \\ Ikuko Ueda \\ Keio University Hospital: Keio Gijuku Daigaku Byoin

\section{Keiichi Fukuda} \\ Keio University Hospital: Keio Gijuku Daigaku Byoin

\section{Shun Kohsaka ( $\nabla$ sk@keio.jp) \\ Keio University School of Medicine}

Keio University Hospital: Keio Gijuku Daigaku Byoin https://orcid.org/0000-0002-6909-0740

\section{Original investigation}

Keywords: Stable ischemic heart disease, Diabetes Mellitus, Canadian Cardiovascular Society functional classification, Percutaneous coronary intervention

Posted Date: September 27th, 2021

DOI: https://doi.org/10.21203/rs.3.rs-892501/v1

License: (c) (i) This work is licensed under a Creative Commons Attribution 4.0 International License. Read Full License 


\section{Abstract}

Background: While angina severity is pertinent in determining the management strategy for patients with stable ischemic heart disease (SIHD), its contributing factors and prognostic effect remain unclear, particularly in patients with diabetes mellitus (DM).

Methods: From a multicenter percutaneous coronary intervention $(\mathrm{PCI})$ registry, 1,911 consecutive SIHD patients without previous revascularization or heart failure between 2008 and 2015 were analyzed. Angina severity was assessed by the Canadian Cardiovascular Society (CCS) functional classification at the time of PCI. We assessed the contributing factors of CCS III/IV angina. Further, the association between CCS III/IV angina and subsequent occurrence of major adverse cardiac and cerebrovascular events (MACCE: all-cause death, acute coronary syndrome, heart failure, and stroke) within 2 years were analyzed in patients with DM and without DM.

Results: A total of 771 SIHD patients (40.3\% of all SIHD patients) had DM at the time of revascularization. In the total cohort, $52.4 \%$ had CCS I/II, and $13.0 \%$ had CCS III/IV angina, with less prevalence of CCS III/IV angina in patients with DM than in those without DM (11.3\% vs. $14.2 \%, P<0.001)$. In patients with $\mathrm{DM}$, the prevalence of unprotected left main coronary trunk lesions and proximal left anterior descending lesion increased with angina severity. The presence of severe angina at the time of PCl was associated with MACCE in patients with DM (adjusted hazard ratio 1.93; [95\% Cl 1.01, 3.71]; $\mathrm{P}=0.047$ ), while no significant difference in those without $\mathrm{DM}$ (adjusted hazard ratio $0.82 ;[95 \% \mathrm{Cl} 0.42,1.59] ; \mathrm{P}=0.55$ ).

Conclusions: In SIHD patients with DM that underwent PCI, severe angina at the time of revascularization was associated with complex coronary anatomies and long-term outcomes. These findings underscore the importance of evaluating angina-related health status while considering revascularization in SIHD patients with DM.

\section{Background}

The prevalence of diabetes mellitus (DM) is increasing globally and has become a leading cause of death in developed countries.[1] Furthermore, approximately $40 \%$ of patients with stable ischemic heart disease (SIHD) who undergo revascularization have DM.[2] Despite comprehensive cardiovascular risk reduction strategies in patients with SIHD, the number of patients with concomitant DM has recently increased, with the incidence of major adverse cardiac and cerebrovascular events (MACCE) being higher in these patients than in those without DM,[3, 4] even with successful percutaneous coronary intervention $(\mathrm{PCl})$.[5] These findings suggest that further risk stratification is required to improve the care and outcomes of SIHD patients with DM.

Measurement of patients' symptom severity is increasingly becoming a pertinent component of tailoring the management strategy for SIHD and has been reported to have potential prognostic utility.[6] However, little is known with regard to its distribution at the point of revascularization or its association with post-revascularization outcomes in the contemporary era. This is partly due to the exclusion of patients with severe or unacceptable level of angina from clinical trials. In fact, of the participants in the Clinical Outcomes Utilizing Revascularization and Aggressive Drug Evaluation (COURAGE) trial, only $21.1 \%$ had Canadian Cardiovascular Society (CCS) class III angina and patients with class IV were excluded.[7] Similarly, in the International Study of Comparative Health Effectiveness with Medical and Invasive Approaches (ISCHEMIA) trial, $95.6 \%$ of the patients had CCS class II angina or less despite the fact that most participants had moderate to severe inducible myocardial ischemia.[8] Hence, observational studies with less-stringent inclusion criteria may provide a more realistic assessment of the distribution and severity of angina in the community, especially for severe angina, such as CCS III or IV.

This study aimed to describe 1) the association of the incidence of MACCE with DM status, 2) distribution of and contributing factors for severe angina stratified by DM status, and 3) association of angina severity with the incidence of major adverse cardiac events in SIHD patients stratified by the presence of DM. Angina severity at the point of 
revascularization is almost universally available, and its association with long-term prognoses would be directly applicable for risk stratification in daily practice and future studies.

\section{Methods}

\section{Study design}

The Japan Cardiovascular Database-Keio Interhospital Cardiovascular Studies (JCD-KiCS), a large, ongoing, prospective, multicenter PCl registry developed in collaboration with the National Cardiovascular Data Registry (NCDR) CathPCI Registry, was designed to collect clinical data from 15 institutes in Japan of consecutive patients undergoing PCI.[9-11] All PCl procedures were performed under the direction of the intervention team of each participating hospital. All patients who consented to participate in this study were followed up by dedicated clinical research coordinators specifically trained in the present $\mathrm{PCl}$ registry. They were instructed to register data from consecutive hospital visits using an electronic datacapturing software system equipped with a data query engine and validations to maintain data quality. Data entered were checked for completeness and internal consistency and its quality was assured through automatic system validation and assessment of data completeness. All participants provided verbal or written consent for data collection. The study protocol was conducted in accordance with the principles of the Declaration of Helsinki and approved by the ethics committee of each participating hospital.

\section{Participants}

A total of 3,463 consecutive SIHD patients who successfully underwent PCI and were discharged between July 2008 and December 2015 were enrolled. We excluded patients with prior revascularization $(n=1,268)$, with heart failure at admission $(n=202)$, and with missing values for CCS $(n=82)$ (Fig. 1).

\section{Definition of Variables}

Angina severity assessed by the CCS is recommended in international clinical practice guidelines as part of a formal structured assessment of a patient's disease-specific health status. [12] The CCS angina classification system is a symptom severity scale from the physician's perspective used to grade symptoms associated with physical activity on 5 levels: class 0 indicates no angina even with strenuous exertion; class I indicates angina only with strenuous exertion; class II indicates angina with walking $>200$ yards on a flat surfaces, climbing stairs rapidly, or in cold or emotional situations; class III indicates angina with walking 100-200 yards on flat surfaces; and class IV indicates angina at rest or with any physical activity.[13] We defined angina severity as no angina (CCS 0), mild angina (CCS I or II), and severe angina (CCS III or IV). In our cohort, each patient's CCS class was evaluated at admission by an attending cardiologist. We were able to query the attending cardiologists to confirm the CCS classification as needed. Since the JCD-KiCS was developed in collaboration with the NCDR Cath PCI registry, the majority of clinical variables and in-hospital outcomes were defined in accordance with its data dictionary (version 4.1).[11] DM was defined as a history of DM or prescriptions for glucose-lowering medications. Chronic kidney disease (CKD) was defined as an estimated glomerular filtration rate of $<60 \mathrm{~mL} / \mathrm{min} / 1.73 \mathrm{~m}^{2}$, which is compatible with the National Kidney Foundation's Kidney Disease Outcomes Quality Initiative and Kidney Disease Improving Global Outcomes classification Stage 3 or higher.[14] Acute coronary syndrome (ACS) was defined as ST elevation myocardial infarction (STEMI) and non-ST elevation acute coronary syndrome (NSTEACS). STEMI was diagnosed by the treating physician at each participating hospital according to the clinical presentation, presence of ST-segment elevation, Q waves and/or a new left bundle branch block on electrocardiogram, and elevated cardiac biomarkers exceeding the upper limit of normal value and consistent with or suggestive of ischemia. NSTE-ACS was also diagnosed by the treating physicians at each participating hospital according to the clinical presentation, cardiac biomarkers, and absence of ST-segment elevation.[15, 16] A multivessel lesion was defined as coronary artery disease involving $\geq 2$ coronary arteries. 


\section{Outcomes}

The primary outcome was defined as the composite of all-cause death, new-onset ACS, non-fatal ischemic stroke, and new-onset heart failure within 2 years. The secondary outcome was defined as the composite of cardiovascular death, new-onset ACS, and new-onset heart failure within 2 years. To ensure the accuracy of the endpoints, the JCD-KiCS was supported by an events committee that included board-certified cardiologists (M.S. and S.K.). Initially, all endpoints were reviewed by a trained clinical research coordinator under the supervision of the project coordinator (I.U.) and categorized based on the need for adjudication or not. One committee member reviewed the abstracted record; a second or third adjudicator was called if there was a disagreement between the project coordinator and the first adjudicator.

\section{Statistical analysis}

Baseline characteristics were summarized by the presence of DM. Continuous variables were summarized as medians with interquartile ranges and compared by Mann-Whitney $U$ tests; categorical variables were summarized as frequencies and compared by chi-square or Fisher's exact test, as appropriate. We stratified angina severity according to the presence of DM and compared the proportion of high-risk coronary anatomies such as unprotected left main coronary trunks (LMTs), proximal left anterior descending arteries ( $\mathrm{pLADs}$ ), or multivessel lesions in each category of angina severity. Multivariable logistic regression analyses, which were adjusted for age, sex, body mass index (BMI), hypertension, CKD, prescriptions for both dual antiplatelet drugs and statins, unprotected LMT lesions, pLAD lesions, and multivessel lesions, were performed for the presence of severe angina in the total cohort, patients with DM, and those without DM. An interaction $\mathrm{P}$ value was calculated to determine whether the association of severe angina at the time of PCl with coronary anatomy was dependent on DM status. We used the Kaplan-Meier method to estimate the incidence of long-term outcomes with $95 \%$ confidence intervals (Cls) stratified by DM status and compared them using the log-rank test. We performed multivariable Cox proportional hazard analyses to evaluate the association of DM with the incidence of MACCE and adjusted for age, sex, BMI, CKD, prescriptions for both dual antiplatelet drugs and statins at discharge, unprotected LMT lesions, pLAD lesions, and multivessel lesions, which were selected based on clinical significance. Then, we stratified patients by DM status and calculated the incidence rate of the long-term outcomes using the Kaplan-Meier method for each category of angina severity, which were then compared using the log-rank test. We performed multivariable Cox proportional hazard analysis to evaluate the association of angina severity (with no angina as a reference) with the incidence of MACCE adjusted for age, sex, BMI, CKD, prescriptions for both dual antiplatelet drugs and statins at discharge, unprotected LMT lesions, pLAD lesions, and multivessel lesions in patients with or without DM. Two-sided P values of $<0.05$ were considered statistically significant. All statistical analyses were performed using $\mathrm{R}$ statistical software (version 4.0.4; The R Foundation for Statistical Computing, Vienna, Austria).[17]

\section{Results}

A total of 1,911 patients with SIHD without prior revascularization or heart failure at admission were analyzed, of which 771 patients (40.3\%) had DM (Fig. 1). The distribution of CCS class 0 , I or II, and III or IV at baseline was $40.1 \%$ and $48.6 \%$, $11.3 \%$ and $30.9 \%$, and $54.9 \%$ and $14.2 \%$ in patients with DM and those without DM, respectively $(P<0.001)$. Patients with DM were more likely to be male and to have comorbidities, such as hypertension, dyslipidemia, and CKD, and multivessel disease (Table 1). 
Table 1

Baseline characteristics according to DM status

\begin{tabular}{|c|c|c|c|}
\hline Characteristic & Patients with DM, N= 771 & Patients without $\mathrm{DM}, \mathrm{N}=1,140$ & $P$ value \\
\hline Age (years) & $69(62,75)$ & $70(63,76)$ & 0.058 \\
\hline Female (\%) & $144(18.7 \%)$ & $276(24.3 \%)$ & 0.004 \\
\hline BMI $\left(\mathrm{kg} / \mathrm{m}^{2}\right)$ & $24.3(22.3,26.7)$ & $23.9(22.1,26.0)$ & 0.004 \\
\hline Hypertension (\%) & $641(83.2 \%)$ & $845(74.5 \%)$ & $<0.001$ \\
\hline Dyslipidemia (\%) & $538(69.9 \%)$ & $714(63.0 \%)$ & 0.002 \\
\hline CKD (\%) & $331(44.3 \%)$ & $396(35.9 \%)$ & $<0.001$ \\
\hline HFrEF (\%) & $19(2.5 \%)$ & $23(2.0 \%)$ & 0.5 \\
\hline PAD (\%) & $106(13.7 \%)$ & $136(12.0 \%)$ & 0.3 \\
\hline Past history of MI (\%) & $54(7.0 \%)$ & $66(5.8 \%)$ & 0.3 \\
\hline Past history of HF (\%) & $50(6.5 \%)$ & $41(3.6 \%)$ & 0.004 \\
\hline Number of antianginal drugs (\%) & & & 0.3 \\
\hline 0 & $681(88.3 \%)$ & $981(86.1 \%)$ & \\
\hline 1 & $69(8.9 \%)$ & $123(10.8 \%)$ & \\
\hline more than 1 & $21(2.7 \%)$ & $36(3.2 \%)$ & \\
\hline Anginal severity (\%) & & & $<0.001$ \\
\hline $\operatorname{ccs} 0$ & $309(40.1 \%)$ & $352(30.9 \%)$ & \\
\hline $\operatorname{cCS} I$ & $133(17.3 \%)$ & $200(17.5 \%)$ & \\
\hline cCs ॥ & $242(31.4 \%)$ & $426(37.4 \%)$ & \\
\hline CCS III or IV & $87(11.3 \%)$ & $162(14.2 \%)$ & \\
\hline Unprotected LMT lesion (\%) & $48(6.2 \%)$ & $60(5.3 \%)$ & 0.4 \\
\hline Proximal LAD lesion (\%) & $286(37.1 \%)$ & $413(36.2 \%)$ & 0.7 \\
\hline Number of diseased vessels (\%) & & & $<0.001$ \\
\hline 1 & $353(45.8 \%)$ & $651(57.1 \%)$ & \\
\hline 2 & $271(35.1 \%)$ & $357(31.3 \%)$ & \\
\hline 3 & $147(19.1 \%)$ & $132(11.6 \%)$ & \\
\hline Optimal medical therapy (\%) & $536(69.6 \%)$ & $838(73.7 \%)$ & 0.051 \\
\hline Aspirin at discharge (\%) & $754(98.4 \%)$ & $1,118(98.6 \%)$ & 0.8 \\
\hline P2Y12 inhibitors at discharge (\%) & $736(95.5 \%)$ & $1,087(95.4 \%)$ & $>0.9$ \\
\hline Statin at discharge (\%) & $561(73.2 \%)$ & $883(77.9 \%)$ & 0.019 \\
\hline Beta blockers at discharge (\%) & $405(52.8 \%)$ & $572(50.4 \%)$ & 0.3 \\
\hline RAASi at discharge (\%) & $453(59.1 \%)$ & $535(47.1 \%)$ & $<0.001$ \\
\hline
\end{tabular}


Data presented as median [interquartile range (IQR)] or $\mathrm{n}(\%)$. CKD was defined as estimated glomerular filtration rate of less than $60 \mathrm{ml} / \mathrm{min} / 1.73 \mathrm{~m}^{2}$. HFrEF was defined as ejection fraction of less than $40 \%$. Optimal medical therapy was defined as dual antiplatelet therapy and statins at discharge. Abbreviations: BMI, body mass index; CKD, chronic kidney disease; HFrEF, heart failure with reduced ejection fraction; PAD, peripheral artery disease; MI, myocardial infarction; HF, heart failure; CCS, Canadian Cardiovascular Society functional classification; LMT, left main coronary trunk; LAD, left anterior descending; RAASi, renin-angiotensin-aldosterone system inhibitors

The prevalence of unprotected LMT lesions increased with angina severity regardless of DM status. Similarly, the prevalence of pLAD lesions increased with angina severity in those with $D M$, whereas no association was observed in those without DM. By contrast, the prevalence of multivessel disease was not associated with angina severity regardless of DM status (Fig. 2). In patients with DM, multivariable logistic regression analyses revealed that pLAD lesions were associated with severe angina (adjusted odds ratio [aOR] 1.68 [95\% $\mathrm{Cl} 1.06,2.66] ; P=0.028$ ). In those without DM, female sex (aOR 1.59 [95\% Cl 1.08, 2.33]; $P=0.018)$, absence of hypertension (aOR 0.65 [95\% $\mathrm{Cl} 0.45,0.96] ; P=0.030$ for hypertension), and presence of CKD (aOR 1.57 [95\% Cl 1.09, 2.26]; $P=0.015)$ were associated with severe angina. The interaction analysis demonstrated that the association of high-risk coronary anatomies with severe angina did not depend on the patient's DM status (interaction $P$ value $>0.05$ for all high-risk coronary anatomies, Fig. 3 ).

The median follow-up duration was 1,028 (interquartile range [IQR], 847-1,223) days, and the follow-up compliance rate was $91.7 \%$. The incidence rates of the primary outcome at 2 years did not differ by DM status $(8.2 \%$ and $10 \%$ in patients without and with DM, respectively; $P=0.16$ [log-rank test]); however, patients with SIHD and DM had higher rates of the secondary outcome components than did those without DM (3.3\% and 5.6\% in patients without and with DM, respectively; $P=0.014$ [log-rank test]) (Fig. 4). Multivariable Cox regression models revealed that DM was not associated with the primary or secondary outcome (adjusted hazard ratio [aHR] $1.08[95 \% \mathrm{Cl} 0.79,1.48] ; P=0.63$ and aHR $1.52[95 \% \mathrm{Cl} 0.96$, 2.42]; $P=0.075$, for the primary and secondary outcomes, respectively).

Among patients with DM, severe angina was associated with a higher incidence of the primary outcome after 2 years $(9.1 \%, 9.3 \%$, and $17 \%$ for CCS classes 0 , I or II, III or IV, respectively; $P=0.049$ [log-rank test]), whereas no association was observed with the secondary outcome $(4.9 \%, 5.7 \%$, and $8.2 \%$ for CCS classes 0 , I or II, III or IV, respectively; $P=0.49$ [logrank test]). By contrast, angina severity was not associated with the incidence of the primary or secondary outcome in those without DM $(9.9 \%, 7.5 \%$, and $7.4 \% ; P=0.38$ and $3.2 \%, 3.6 \%$, and $2.5 \% ; P=0.79$ in CCS classes 0 , I or II, III or IV for the primary and secondary outcomes, respectively) (Fig. 5). Multivariable Cox regression models revealed that severe angina was associated with the incidence of the primary outcome (aHR 1.93 [95\% $\mathrm{Cl} 1.01,3.71] ; P=0.047$ ), whereas angina severity was not associated with the incidence of the secondary outcome (aHR $1.71[95 \% \mathrm{Cl} 0.68,4.32] ; P=0.26)$ in patients with DM. In those without DM, the presence of severe angina was not associated with either the primary or secondary outcome (Table 2). 
Table 2

Association of baseline angina severity with long-term outcome according to DM status

\begin{tabular}{|c|c|c|c|c|c|c|c|c|c|c|c|c|}
\hline \multirow[b]{3}{*}{ Characteristic } & \multicolumn{6}{|c|}{ Primary outcome } & \multicolumn{6}{|c|}{ Secondary outcome } \\
\hline & \multicolumn{3}{|c|}{ Patients with DM } & \multicolumn{3}{|c|}{ Patients without DM } & \multicolumn{3}{|c|}{ Patients with DM } & \multicolumn{3}{|c|}{ Patients without DM } \\
\hline & $\mathrm{HR}$ & $\begin{array}{l}95 \% \\
\mathrm{Cl}\end{array}$ & $\begin{array}{l}P \\
\text { value }\end{array}$ & $\mathrm{HR}$ & $\begin{array}{l}95 \% \\
\mathrm{Cl}\end{array}$ & $\begin{array}{l}P \\
\text { value }\end{array}$ & $\mathrm{HR}$ & $\begin{array}{l}95 \% \\
\mathrm{Cl}\end{array}$ & $\begin{array}{l}P \\
\text { value }\end{array}$ & $\mathrm{HR}$ & $\begin{array}{l}95 \% \\
\mathrm{Cl}\end{array}$ & $\begin{array}{l}P \\
\text { value }\end{array}$ \\
\hline \multicolumn{13}{|l|}{$\begin{array}{l}\text { Anginal } \\
\text { severity }\end{array}$} \\
\hline $\operatorname{ccs} 0$ & - & - & & - & - & & - & - & & - & - & \\
\hline CCS I or II & 0.96 & $\begin{array}{l}0.57 \\
1.61\end{array}$ & 0.88 & 0.95 & $\begin{array}{l}0.60 \\
1.49\end{array}$ & 0.81 & 1.05 & $\begin{array}{l}0.52 \\
2.11\end{array}$ & 0.89 & 1.59 & $\begin{array}{l}0.74 \\
3.42\end{array}$ & 0.23 \\
\hline CCS III or IV & 1.93 & $\begin{array}{l}1.01 \\
3.71\end{array}$ & 0.047 & 0.82 & $\begin{array}{l}0.42 \\
1.59\end{array}$ & 0.55 & 1.71 & $\begin{array}{l}0.68 \\
4.32\end{array}$ & 0.26 & 0.99 & $\begin{array}{l}0.31 \\
3.22\end{array}$ & 0.99 \\
\hline Age (years) & 1.03 & $\begin{array}{l}1.00 \\
1.06\end{array}$ & 0.075 & 1.04 & $\begin{array}{l}1.02 \\
1.07\end{array}$ & 0.002 & 1.01 & $\begin{array}{l}0.97 \\
1.04\end{array}$ & 0.76 & 1.01 & $\begin{array}{l}0.97 \\
1.05\end{array}$ & 0.52 \\
\hline Female & 1 & $\begin{array}{l}0.57 \\
1.74\end{array}$ & 0.99 & 0.73 & $\begin{array}{l}0.44 \\
1.21\end{array}$ & 0.22 & 0.97 & $\begin{array}{l}0.45 \\
2.08\end{array}$ & 0.94 & 1.24 & $\begin{array}{l}0.54 \\
2.82\end{array}$ & 0.61 \\
\hline BMI $\left(\mathrm{kg} / \mathrm{m}^{2}\right)$ & 0.96 & $\begin{array}{l}0.89 \\
1.02\end{array}$ & 0.2 & 0.95 & $\begin{array}{l}0.88 \\
1.02\end{array}$ & 0.13 & 0.92 & $\begin{array}{l}0.83 \\
1.01\end{array}$ & 0.091 & 0.92 & $\begin{array}{l}0.83 \\
1.03\end{array}$ & 0.15 \\
\hline CKD & 2.35 & $\begin{array}{l}1.41 \\
3.92\end{array}$ & 0.001 & 1.45 & $\begin{array}{l}0.95 \\
2.22\end{array}$ & 0.083 & 2.4 & $\begin{array}{l}1.21 \\
4.77\end{array}$ & 0.013 & 2.1 & $\begin{array}{l}1.04 \\
4.24\end{array}$ & 0.039 \\
\hline $\begin{array}{l}\text { Optimal } \\
\text { medical } \\
\text { therapy }\end{array}$ & 0.57 & $\begin{array}{l}0.36 \\
0.90\end{array}$ & 0.017 & 0.58 & $\begin{array}{l}0.38 \\
0.90\end{array}$ & 0.014 & 0.84 & $\begin{array}{l}0.44 \\
1.63\end{array}$ & 0.61 & 0.47 & $\begin{array}{l}0.24 \\
0.94\end{array}$ & 0.032 \\
\hline $\begin{array}{l}\text { Unprotected } \\
\text { LMT lesion }\end{array}$ & 2.3 & $\begin{array}{l}1.20 \\
4.42\end{array}$ & 0.013 & 2.46 & $\begin{array}{l}1.32 \\
4.58\end{array}$ & 0.004 & 2.68 & $\begin{array}{l}1.13 \\
6.36\end{array}$ & 0.026 & 1.88 & $\begin{array}{l}0.56 \\
6.28\end{array}$ & 0.31 \\
\hline $\begin{array}{l}\text { Proximal LAD } \\
\text { lesion }\end{array}$ & 1.01 & $\begin{array}{l}0.62 \\
1.63\end{array}$ & 0.98 & 1.24 & $\begin{array}{l}0.81 \\
1.88\end{array}$ & 0.32 & 0.79 & $\begin{array}{l}0.41 \\
1.55\end{array}$ & 0.5 & 0.48 & $\begin{array}{l}0.22 \\
1.08\end{array}$ & 0.075 \\
\hline $\begin{array}{l}\text { Multivessel } \\
\text { lesion }\end{array}$ & 1.2 & $\begin{array}{l}0.75 \\
1.93\end{array}$ & 0.45 & 1.35 & $\begin{array}{l}0.89 \\
2.04\end{array}$ & 0.16 & 1.07 & $\begin{array}{l}0.57 \\
2.01\end{array}$ & 0.84 & 2.07 & $\begin{array}{l}1.05 \\
4.09\end{array}$ & 0.037 \\
\hline
\end{tabular}

The primary outcome was a composite of all-cause death, new-onset acute coronary syndrome, and non-fatal ischemic stroke within 2-year and the secondary outcome was a composite of cardiovascular death, new-onset acute coronary syndrome, and heart failure within 2-year. CKD was defined as estimated glomerular filtration rate of less than 60 $\mathrm{ml} / \mathrm{min} / 1.73 \mathrm{~m}^{2}$. Optimal medical therapy was defined as dual antiplatelet therapy and statins at discharge. Abbreviations: CCS, Canadian Cardiovascular Society functional classification; BMI, body mass index; CKD, chronic kidney disease; LMT, left main coronary trunk; LAD, left anterior descending; HR, hazard ratio; $\mathrm{Cl}$, confidence interval

\section{Discussion}

In a large-scale, contemporary multicenter PCI registry, we observed that 1) the incidence of MACCE did not differ among patients with SIHD and DM from those without DM; 2) patients with SIHD and DM who had CCS III or IV angina had a high prevalence of high-risk coronary anatomies, such as unprotected LMT and PLAD lesions; and 3) the presence of CCS III or IV angina was associated with the incidence of MACCE in patients with DM.

While several randomized controlled trials (RCTs) and observational studies countries have reported that patients with SIHD and DM have a high incidence of MACCE in Western population,[8, 18-20] observational studies have indicated that 
the DM-associated risk of MACCE was attenuated for patients with SIHD who underwent revascularization in Japan that consistent with our results. [21, 22] This discrepancy might be explained by the fact that Japanese patients with DM have a lower degree of hyperinsulinemia and insulin resistance than Western patients with DM. Our analysis indicated that Japanese patients with SIHD and DM could differ from their Western counterparts and may need risk stratification tools that are specific for Japanese patients with SIHD and DM.

Previous studies on the association of angina severity with long-term prognoses have provided mixed results, especially in those with DM.[19, 23-25] A meta-analysis of pivotal RCTs that included 5,034 patients with SIHD and DM revealed that CCS III or IV angina had higher incidences of MACCE, but the association was attenuated after adjusting for baseline characteristics.[26] Moreover, the large-size outpatient-based CLARIFY registry (ProspeCtive observational LongitudinAI Reglstry of patients with stable coronary arterY disease) has revealed that the presence of angina solely was not associated with the incidence of subsequent myocardial infarction or all-cause death.[19] However, RCTs in this metaanalysis excluded patients who had unprotected LMT lesions or persistent severe angina.[7, 27, 28] Further, the CLARIFY registry excludes patients with planned revascularization, such as in cases of severe angina or high-risk coronary anatomies.[19, 29] The JCD-KiCS enrolled all consecutive patients who underwent PCI without any exclusion criteria. Therefore, our cohort may include a more comprehensive list of patients including those with SIHD and high-risk coronary anatomies and of the degree of patients with angina that would reflect a real-world setting. It is noteworthy that such a high prevalence of unprotected LMT lesions in patients with SIHD and concomitant DM with CCS III or IV angina was observed in our analysis and in previous studies.[30,31] Patients with SIHD and DM who have severe angina with limited functional capacity would be reasonable candidates to undergo evaluation of their coronary anatomy before deciding on conservative management because such high-risk lesions remain a primary indication for revascularization even after pivotal RCTs, such as the COURAGE and ISCHEMIA trials.[7, 8] Further, our findings indicated that the contributing factors and prognostic implications of CCS III or IV differed by DM status. A possible explanation might be ischemic burden and cardiac autonomic neuropathies. Myocardial ischemia, which was recognized as angina, is transmitted by sympathetic nerve fibers that would be affected by neuropathies.[32] Therefore, the magnitude of angina would be influenced by both ischemic burden and cardiac autonomic neuropathies such as DM. The occurrence of CCS III or IV angina in patients with SIHD and DM with an impaired perception of angina would imply a greater ischemic burden and less myocardial reserve for hypoxemia than in those without DM.

In risk models that have evaluated the incidence of MACCE in patients with SIHD,[33, 34] pertinent variables were patients' baseline characteristics and coronary lesion complexity requiring costly and invasive procedures.[35, 36] Our study revealed that patients' functional status at the time of revascularization was an independent predictor of their long-term prognosis even after adjusting for clinical characteristics and high-risk coronary anatomies in patients with SIHD and DM. As it is easy to obtain from patients, the degree of angina and functional status could help determine the specific types and intensity of interventions, particularly when considering coronary revascularization.

This study is best understood in the context of several limitations. First, our registry did not include patients who were treated medically or with coronary artery bypass grafting (CABG), which led to selection biases. Especially, since CABG is the preferred line of treatment for revascularization in patients with SIHD and DM with multivessel disease, excluding patients who had CABG would alter the results. Second, SIHD patients with CCS 0 (silent ischemia) might have a high-risk clinical profile because they would have indications of $\mathrm{PCl}$ other than symptoms alleviation. However, such selection bias is likely to attenuate rather than strengthen the prognostic implication of angina severity; therefore, our results would be robust. Third, we did not enroll patients with non-obstructive coronary artery disease. Given that patients with nonobstructive coronary artery disease had better prognoses than did those with established coronary artery disease,[37] our results do not apply to such a population. Fourth, we assessed angina severity using the CCS that is known to have limited reproducibility and sensitivity to important clinical changes. Recently, patient reported outcomes such as the Seattle Angina Questionnaire were recommended for use in clinical trials and daily practice. ${ }^{7}$ Further studies that evaluate 
the prognostic implication for angina severity assessed by the Seattle Angina Questionnaire are warranted. Lastly, we did not measure the residual angina after $\mathrm{PCl}$ in patients, which is known to have a risk for future MACCE. ${ }^{5}$ However, the main purpose of this analysis was to examine the clinical implications of angina severity at the point of $\mathrm{PCI}$ rather than to assess the treatment effects of PCl.

\section{Conclusions}

ACS: acute coronary syndrome; BMI: body mass index; CABG: coronary artery bypass grafting; CCS: the Canadian Cardiovascular Society functional classification; Cl: confidence interval; CKD: chronic kidney disease; CLARIFY: prospective observational longitudinal registry of patients with stable coronary artery disease registry; COURAGE: the Clinical Outcomes Utilizing Revascularization and Aggressive Drug Evaluation trial; DM: diabetes mellitus; GFR: glomerular filtration rate; HR: hazard ratio; IQR: interquartile range; ISCHEMIA: the International Study of Comparative Health Effectiveness with Medical and Invasive Approaches trial; JCD-KiCS: Japan Cardiovascular Database-Keio interhospital Cardiovascular Studies; LAD: left anterior descending arteries; LMT: left main coronary trunks; MACCE: major adverse cardiac and cerebrovascular events; NCDR: National Cardiovascular Data Registry; NSTE-ACS: non-ST elevation acute coronary syndrome; OR: odds ratio; PCI: percutaneous coronary intervention; RCT: randomized controlled trial; SIHD: stable ischemic heart disease; STEMI: ST elevation myocardial infarction.

\section{Abbreviations}

ACS

acute coronary syndrome; BMI:body mass index; CABG:coronary artery bypass grafting; CCS:the Canadian Cardiovascular Society functional classification; Cl:confidence interval; CKD:chronic kidney disease; CLARIFY:prospective observational longitudinal registry of patients with stable coronary artery disease registry; COURAGE:the Clinical Outcomes Utilizing Revascularization and Aggressive Drug Evaluation trial; DM:diabetes mellitus; GFR:glomerular filtration rate; HR:hazard ratio; IQR:interquartile range; ISCHEMIA:the International Study of Comparative Health Effectiveness with Medical and Invasive Approaches trial; JCD-KiCS:Japan Cardiovascular Database-Keio interhospital Cardiovascular Studies; LAD:left anterior descending arteries; LMT:left main coronary trunks; MACCE:major adverse cardiac and cerebrovascular events; NCDR:National Cardiovascular Data Registry; NSTE-ACS:non-ST elevation acute coronary syndrome; OR:odds ratio; PCl:percutaneous coronary intervention; RCT:randomized controlled trial; SIHD:stable ischemic heart disease; STEMI:ST elevation myocardial infarction.

\section{Declarations}

\section{Ethics approval and consent to participate}

The Ethics Committee of Keio University and each institutions approved this study.

\section{Consent for publication}

Not applicable.

\section{Availability of data and materials}

The datasets used and/or analyzed during the current study are available from the corresponding author on reasonable request. 


\section{Competing interests}

S.K. received a grant from Daiichi Sankyo during the conduct of the study; and grants from Novartis and personal fees from Bristol-Myers Squibb outside the submitted work. No other conflicts of interest relevant to this article exist.

\section{Funding}

This work was supported by Grants-in-Aid for Scientific Research from the Japan Society for the Promotion of Science (KAKENHI; Nos. 20H03915, https://kaken.nii.ac.jp/ja/index/). The funders played no role in the design and conduct of the study; collection, management, analysis, and interpretation of the data; review, or approval of the manuscript; and decision to submit the manuscript for publication.

\section{Authors' contributions}

Nozomi Niimi: Conceptualization, Formal analysis, Methodology, Writing-original draft Satoshi Shoji: Methodology, Writing-review and editing, Supervision Mitsuaki Sawano: Methodology, Data curation, Writing-review and editing, Supervision Nobuhiro Ikemura: Methodology, Writing-review and editing Yasuyuki Shiraishi: Methodology, Writing-review and editing, Supervision Taku Inohara: Methodology, Writing-review and editing, Supervision Ikuko Ueda: Project administration, Data curation Keiichi Fukuda: Funding acquisition, Writing-review and editing, Supervision Shun Kohsaka: Conceptualization, Funding acquisition, Methodology, Project administration, Resources, Data curation, Writingreview and editing, Supervision. All authors have read and agreed to the published version of the manuscript.

\section{Acknowledgments}

We would like to thank all study coordinators, investigators, and patients who participated in the JCD-KiCS registry. We also would like to thank Editage (www.editage.com) for English language editing.

\section{References}

1. Cho NH, Shaw JE, Karuranga S, Huang Y, da Rocha Fernandes JD, Ohlrogge AW, et al. IDF Diabetes Atlas: Global estimates of diabetes prevalence for 2017 and projections for 2045. Diabetes Res Clin Pract Elsevier BV. 2018;138:271-81.

2. Inohara T, Kohsaka S, Spertus JA, Masoudi FA, Rumsfeld JS, Kennedy KF, et al. Comparative Trends in Percutaneous Coronary Intervention in Japan and the United States, 2013 to 2017. J Am Coll Cardiol. 2020;76:1328-40.

3. Arnold SV, Bhatt DL, Barsness GW, Beatty AL, Deedwania PC, Inzucchi SE, et al. Clinical Management of Stable Coronary Artery Disease in Patients with Type 2 Diabetes Mellitus: A Scientific Statement from the American Heart Association. Circulation. 2020;141:E779-806.

4. Donahoe SM, Stewart GC, McCabe CH, Mohanavelu S, Murphy SA, Cannon CP, et al. Diabetes and Mortality Following Acute Coronary Syndromes. JAMA. 2007;298:765.

5. Grodzinsky A, Kosiborod M, Tang F, Jones PG, McGuire DK, Spertus JA, et al. Residual Angina After Elective Percutaneous Coronary Intervention in Patients With Diabetes Mellitus. Circ Cardiovasc Qual Outcomes. 2017;10:1-7.

6. Spertus JA, Jones P, McDonell M, Fan V, Fihn SD. Health status predicts long-term outcome in outpatients with coronary disease. Circulation. 2002;106:43-9.

7. Boden WE, O'Rourke RA, Teo KK, Hartigan PM, Maron DJ, Kostuk WJ, et al. Optimal Medical Therapy with or without PCI for Stable Coronary Disease. N Engl J Med Massachusetts Medical Society. 2007;356:1503-16. 
8. Maron DJ, Hochman JS, Reynolds HR, Bangalore S, O’Brien SM, Boden WE, et al. Initial Invasive or Conservative Strategy for Stable Coronary Disease. N Engl J Med. 2020;382:1395-407.

9. Inohara T, Miyata H, Ueda I, Maekawa Y, Fukuda K, Kohsaka S. Use of Intra-aortic Balloon Pump in a Japanese Multicenter Percutaneous Coronary Intervention Registry. JAMA Intern Med. 2015;175:1980-2.

10. Inohara T, Kohsaka S, Miyata H, Ueda I, Maekawa Y, Fukuda K, et al. Performance and Validation of the U.S. NCDR Acute Kidney Injury Prediction Model in Japan. J Am Coll Cardiol. 2016;67:1715-22.

11. Kohsaka S, Miyata H, Ueda I, Masoudi FA, Peterson ED, Maekawa Y, et al. An international comparison of patients undergoing percutaneous coronary intervention: A collaborative study of the National Cardiovascular Data Registry (NCDR) and Japan Cardiovascular Database-Keio interhospital Cardiovascular Studies (JCD-KiCS). Am Heart J Mosby Inc. 2015;170:1077-85.

12. Fihn SD, Gardin JM, Abrams J, Berra K, Blankenship JC, Dallas AP, et al 2012 ACCF/AHA/ACP/AATS/PCNA/SCAI/STS Guideline for the Diagnosis and Management of Patients With Stable Ischemic Heart Disease. Circulation. American Heart Association; 2012;126:e354-471.

13. Knuuti J, Wijns W, Saraste A, Capodanno D, Barbato E, Funck-Brentano C, et al. 2019 ESC Guidelines for the diagnosis and management of chronic coronary syndromes. Eur Heart J. 2020;41:407-77.

14. Eckardt KU, Berns JS, Rocco MV, Kasiske BL. Definition and Classification of CKD: The Debate Should Be About Patient Prognosis-A Position Statement From KDOQI and KDIGO. Am J Kidney Dis. 2009;53:915-20.

15. Thygesen K, Alpert JS, Jaffe AS, Chaitman BR, Bax JJ, Morrow DA, et al. Fourth universal definition of myocardial infarction (2018). Eur Heart J. 2019;40:237-69.

16. Collet J-P, Thiele H, Barbato E, Barthélémy O, Bauersachs J, Bhatt DL, et al. 2020 ESC Guidelines for the management of acute coronary syndromes in patients presenting without persistent ST-segment elevation. Eur Heart J. 2020;1-79.

17. R Core Team. R: A Language and Environment for Statistical Computing [Internet]. Vienna, Austria: R Foundation for Statistical Computing; 2020. Available from: https://www.r-project.org/.

18. Maron DJ, Boden WE, Spertus JA, Hartigan PM, Mancini GBJ, Sedlis SP, et al. Impact of Metabolic Syndrome and Diabetes on Prognosis and Outcomes With Early Percutaneous Coronary Intervention in the COURAGE (Clinical Outcomes Utilizing Revascularization and Aggressive Drug Evaluation) Trial. J Am Coll Cardiol. 2011;58:131-7.

19. Sorbets E, Fox KM, Elbez Y, Danchin N, Dorian P, Ferrari R, et al. Long-term outcomes of chronic coronary syndrome worldwide: insights from the international CLARIFY registry. Eur Heart J. 2019;1-10.

20. Cavender MA, Steg PG, Smith SC, Eagle K, Ohman EM, Goto S, et al. Impact of Diabetes Mellitus on Hospitalization for Heart Failure, Cardiovascular Events, and Death. Circulation. 2015;132:923-31.

21. Kohsaka S, Komeda M, Goto M, Sakata R, Nagai T, Ohsugi M, et al. Impact of diabetes among revascularized patients in Japan and the U.S. Diabetes Care. 2012;35:654-9.

22. Tada T, Kimura T, Morimoto T, Ono K, Furukawa Y, Nakagawa Y, et al. Comparison of three-year clinical outcomes after sirolimus-eluting stent implantation among insulin-treated diabetic, noninsulin-treated diabetic, and non-diabetic patients from j-cypher registry. Am J Cardiol. Elsevier Inc.; 2011;107:1155-62.

23. Celik A, Karayakali M, Erkorkmaz U, Altunkas F, Karaman K, Koc F, et al. Presence of angina pectoris is related to extensive coronary artery disease in diabetic patients. Clin Cardiol. 2013;36:475-9.

24. Steg PG, Greenlaw N, Tendera M, Tardif JC, Ferrari R, Al-Zaibag M, et al. Prevalence of anginal symptoms and myocardial ischemia and their effect on clinical outcomes in outpatients with stable coronary artery disease data from the international observational CLARIFY registry. JAMA Intern Med. 2014;174:1651-9.

25. Owlia M, Dodson JA, King JB, Derington CG, Herrick JS, Sedlis SP, et al. Angina Severity, Mortality, and Healthcare Utilization Among Veterans With Stable Angina. J Am Heart Assoc. 2019;8:e012811. 
26. Mancini GBJ, Boden WE, Brooks MM, Vlachos H, Chaitman BR, Frye R, et al. Impact of treatment strategies on outcomes in patients with stable coronary artery disease and type 2 diabetes mellitus according to presenting angina severity: A pooled analysis of three federally-funded randomized trials. Atherosclerosis. 277: Elsevier Ltd; 2018. pp. 186-94.

27. Ferraro R, Latina JM, Alfaddagh A, Michos ED, Blaha MJ, Jones SR, et al. Evaluation and Management of Patients With Stable Angina: Beyond the Ischemia Paradigm: JACC State-of-the-Art Review. J Am Coll Cardiol. 2020;76:225266.

28. BARI 2D Study Group. Frye RL, August P, Brooks MM, Hardison RM, Kelsey SF, et al. A randomized trial of therapies for type 2 diabetes and coronary artery disease. N Engl J Med. 2009;360:2503-15.

29. Sorbets E, Greenlaw N, Ferrari R, Ford I, Fox KM, Tardif JC, et al. Rationale, design, and baseline characteristics of the CLARIFY registry of outpatients with stable coronary artery disease. Clin Cardiol. 2017;40:797-806.

30. Hemingway H, Fitzpatrick NK, Gnani S, Feder G, Walker N, Crook AM, et al. Prospective validity of measuring angina severity with Canadian Cardiovascular Society class: The ACRE study. Can J Cardiol. 2004;20:305-9.

31. Chaitman BR, Bourassa MG, Davis K, Rogers WJ, Tyras DH, Berger R, et al. Angiographic prevalence of high-risk coronary artery disease in patient subsets (CASS). Circulation. 1981;64:360-7.

32. Cohn PF, Fox KM, Daly C. Silent myocardial ischemia. Circulation. 2003;108:1263-77.

33. Daly CA, De Stavola B, Sendon JLL, Tavazzi L, Boersma E, Clemens F, et al. Predicting prognosis in stable anginaresults from the Euro heart survey of stable angina: prospective observational study. BMJ. 2006;332:262-7.

34. Ford I, Robertson M, Greenlaw N, Bauters C, Lemesle G, Sorbets E, et al. Simple risk models to predict cardiovascular death in patients with stable coronary artery disease. European Heart Journal - Quality of Care and Clinical Outcomes. 2020;1-8.

35. Wu C, Camacho FT, King SB, Walford G, Holmes DR, Stamato NJ, et al. Risk stratification for long-term mortality after percutaneous coronary intervention. Circ Cardiovasc Interv. 2014;7:80-7.

36. Boden WE, Hartigan PM, Mancini J, Teo KK, Chaitman BR, Maron DJ, et al. Risk Prediction Tool for Assessing the Probability of Death or Myocardial Infarction in Patients With Stable Coronary Artery Disease. Am J Cardiol. Elsevier Inc.; 2020;130:1-6.

37. Rahman H, Corcoran D, Aetesam-ur-Rahman M, Hoole SP, Berry C, Perera D. Diagnosis of patients with angina and non-obstructive coronary disease in the catheter laboratory. Heart. 2019;105:1536-42.

\section{Figures}




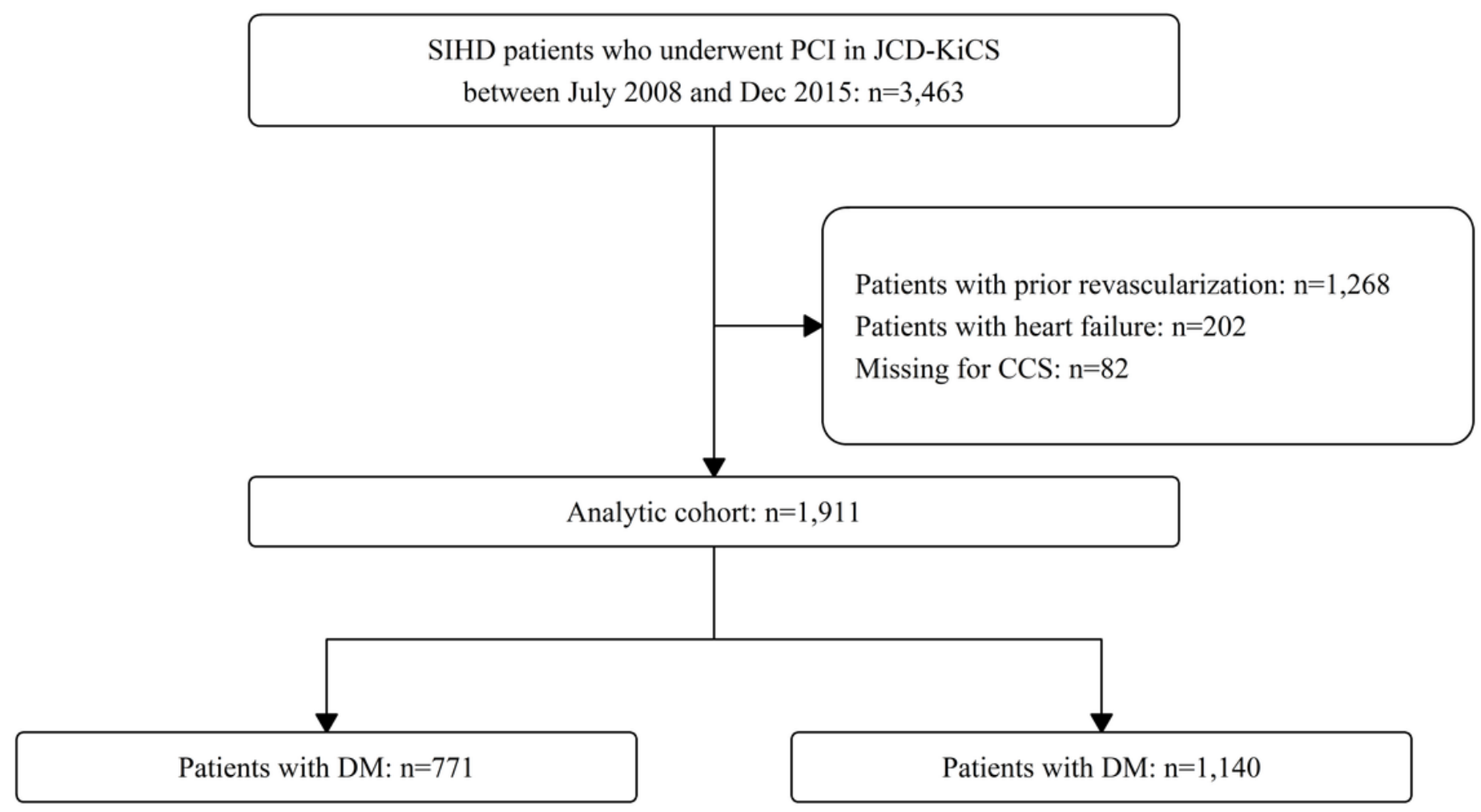

\section{Figure 1}

Study flow chart. Abbreviations: SIHD, stable ischemic heart disease; PCl, percutaneous coronary intervention; JCD-KiCS, The Japan Cardiovascular Database-Keio Interhospital Cardiovascular Studies; CCS, Canadian Cardiovascular Society functional classification; DM, diabetes mellitus. 
The distribution of angina severity according to DM status

Patients without DM, $\mathrm{n}=1,140$ Patients with DM, $\mathrm{n}=771$
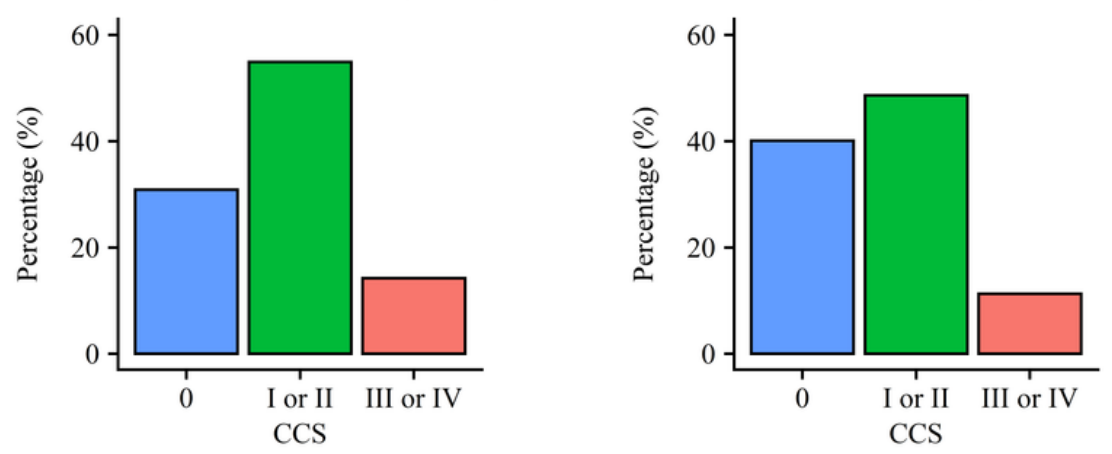

The prevalence of high-risk coronary anatomies according to DM status and angina severity

Unprotected LMT
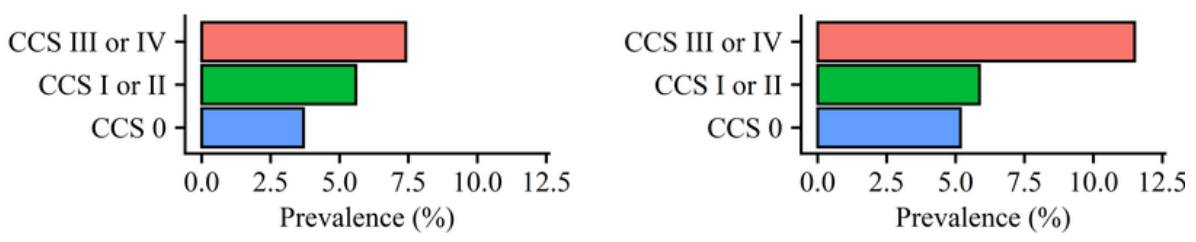

Proximal LAD
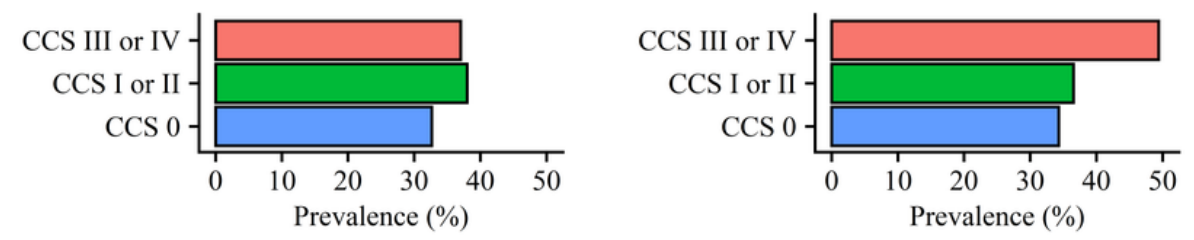

Multivessel disease
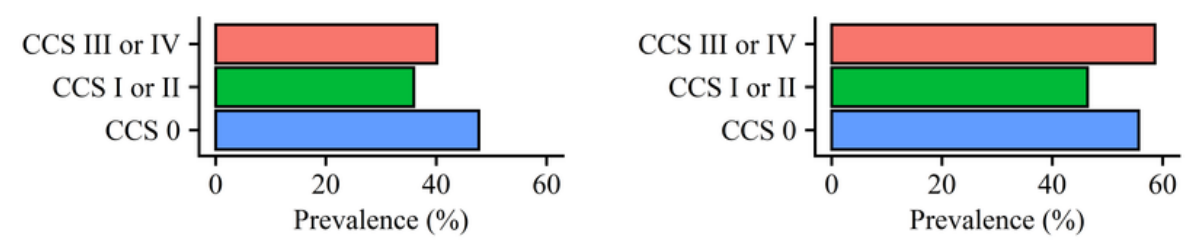

Figure 2

Distribution of angina and its association with the prevalence of high-risk lesions stratified by DM status. Abbreviations: CCS, Canadian Cardiovascular Society functional classification; LMT, left main coronary trunk; DM, diabetes mellitus. 


\section{Multivariable logistic model for CCS III or IV}

- Patients with DM $\square$ Patients without DM

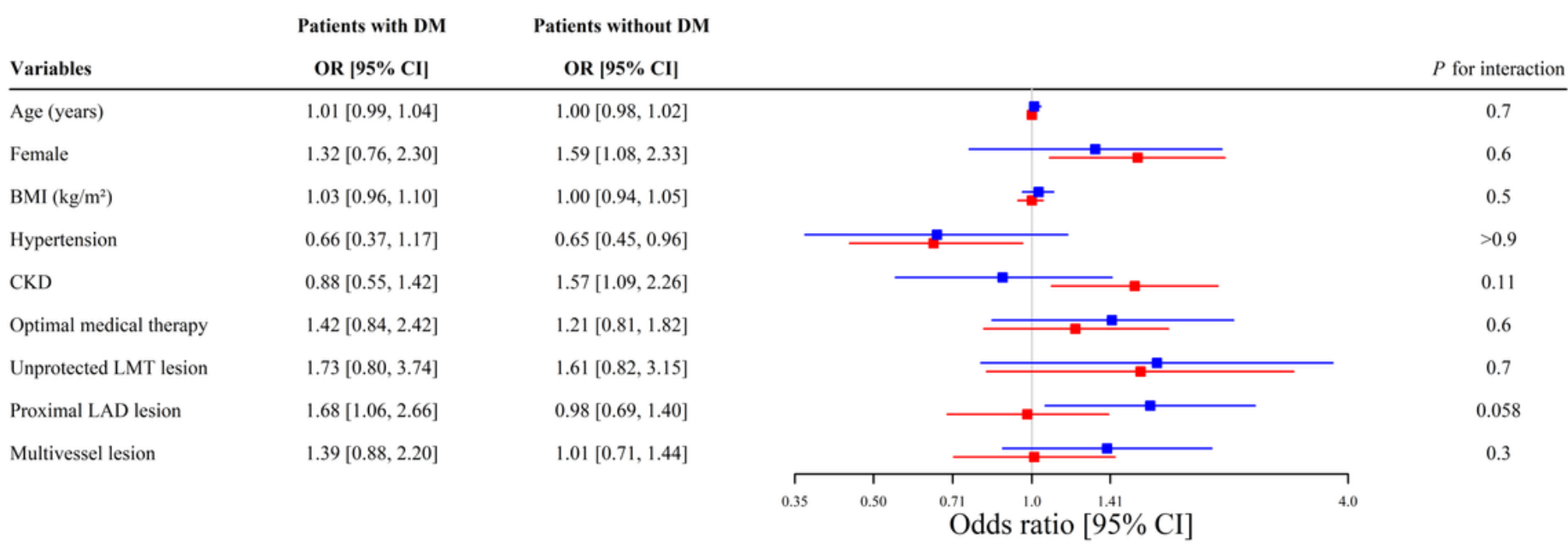

\section{Figure 3}

Forest plot of adjusted odds ratio for CCS III or IV angina stratified by DM status. CKD was defined as estimated glomerular filtration rate of less than $60 \mathrm{ml} / \mathrm{min} / 1.73 \mathrm{~m} 2$. Optimal medical therapy was defined as dual antiplatelet therapy and statins at discharge. Abbreviations: CCS, Canadian Cardiovascular Society functional classification; BMI, body mass index; CKD, chronic kidney disease; LMT, left main coronary trunk; LAD, left anterior descending; DM, diabetes mellitus; OR, odds ratio; $\mathrm{Cl}$ confidence interval 


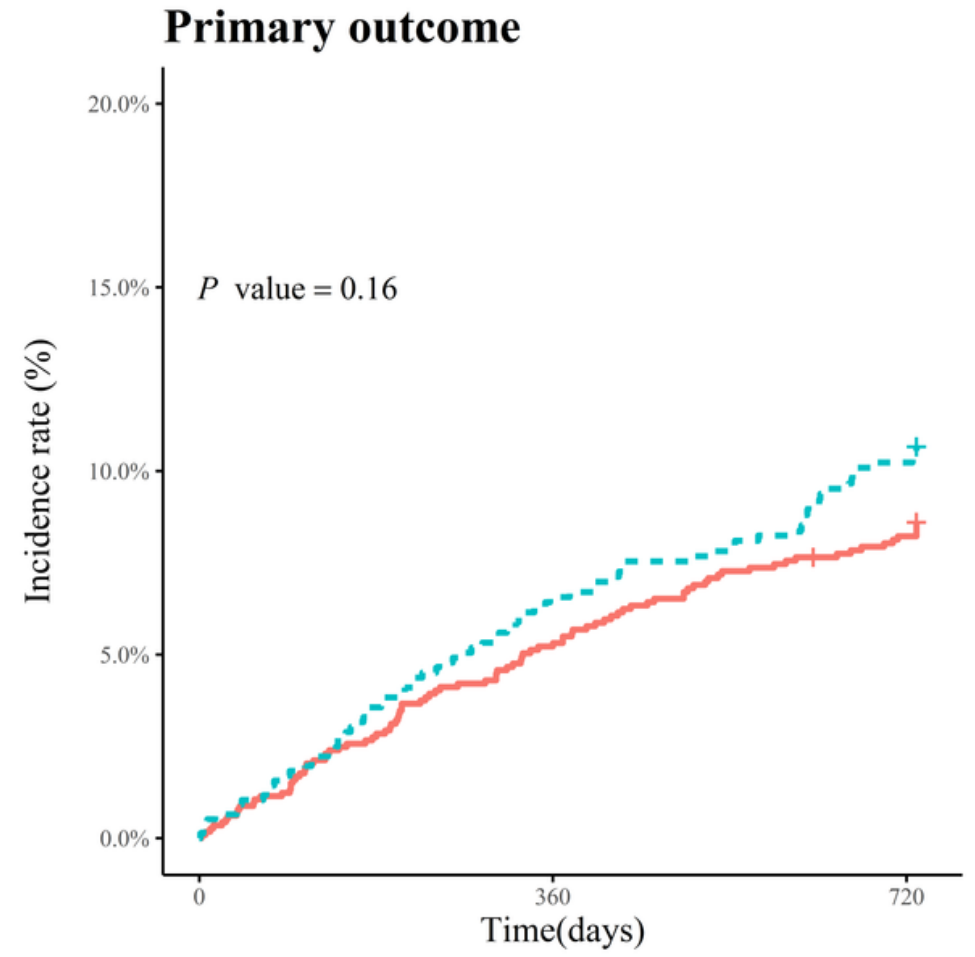

Number at risk

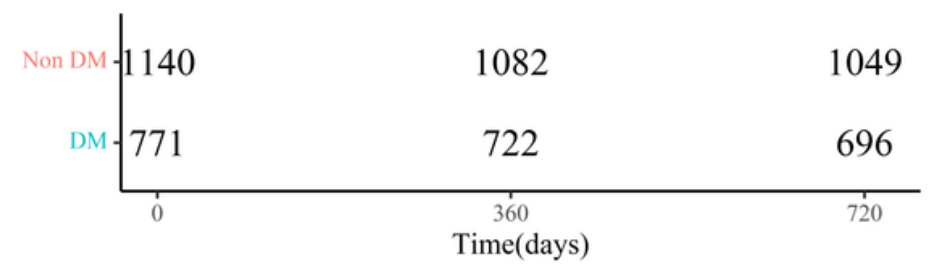

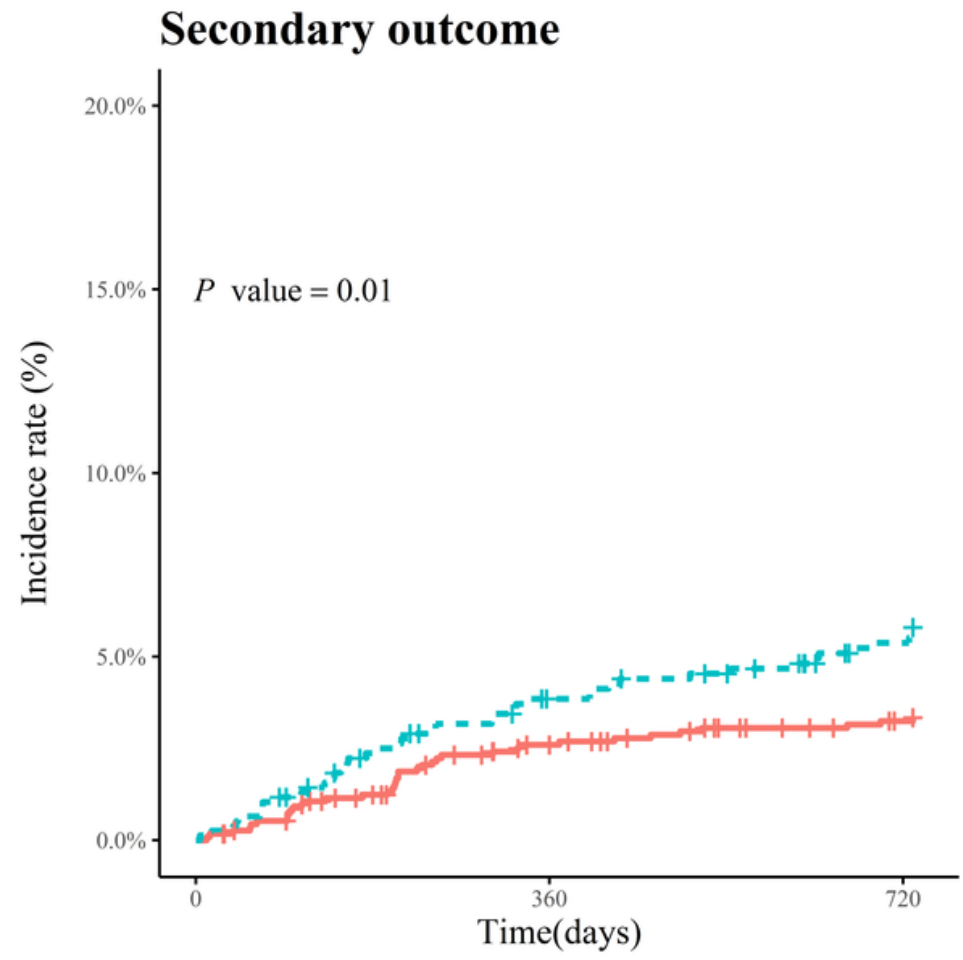

Number at risk

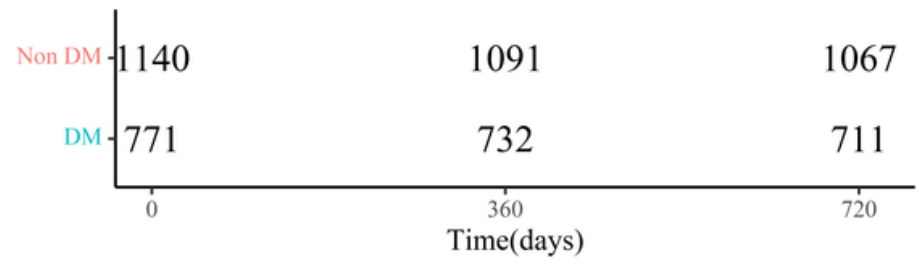

\section{Figure 4}

The association between long-term outcomes and DM status. The primary outcome was defined as a composite of allcause death, new-onset acute coronary syndrome, non-fatal ischemic stroke, and new-onset heart failure within 2 years. The secondary outcome was defined as a composite of cardiovascular death, new-onset acute coronary syndrome, and new-onset heart failure within 2 years. Abbreviation: DM, diabetes mellitus. 
Primary outcome

Patients with DM

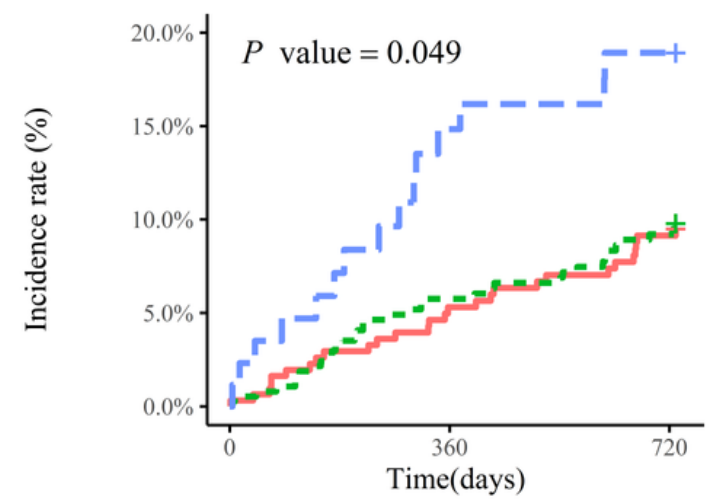

Number at risk

\begin{tabular}{rccc} 
CCS 0 & -309 & 293 & 282 \\
CCS I or II & -375 & 354 & 342 \\
CCS III or IV & -15 & 72 \\
\hline 0 & 360 & 720 \\
\hline & Time(days) &
\end{tabular}

\section{Secondary outcome}

Patients with DM

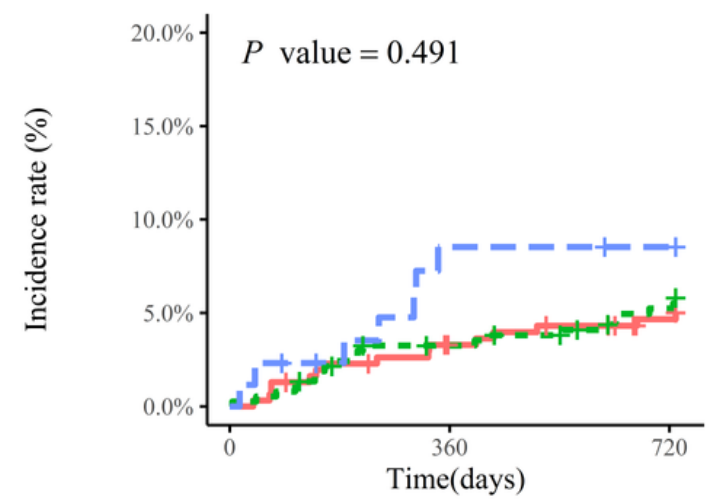

Number at risk

CCS III or IV II -\begin{tabular}{ccc}
-309 & 295 & 286 \\
-375 & 359 & 348 \\
87 & 78 & 77 \\
\hline 0 & Time(days) & 720
\end{tabular}

Primary outcome

Patients without DM

$20.0 \%-\quad P$ value $=0.38$

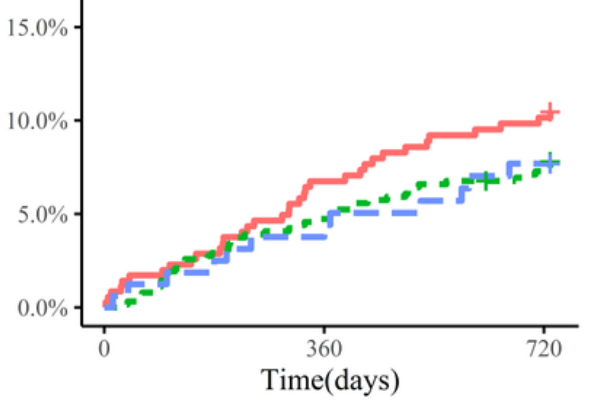

Number at risk

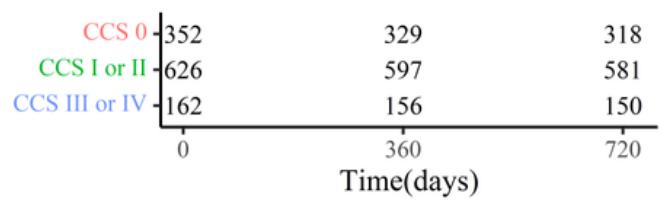

Secondary outcome

Patients without DM

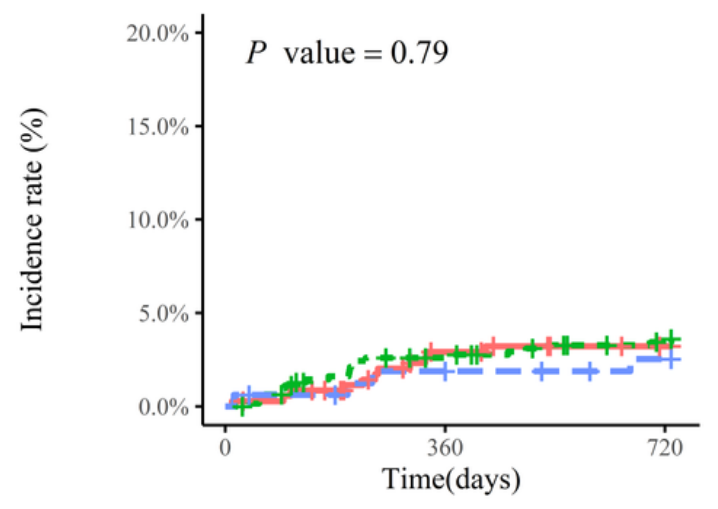

Number at risk

\begin{tabular}{|c|c|c|}
\hline $\operatorname{ccs} 0-352$ & 333 & 326 \\
\hline CCS I or II -626 & 601 & 588 \\
\hline CCS III or IV -162 & 157 & 153 \\
\hline 0 & $\begin{array}{c}360 \\
\text { Time(days) }\end{array}$ & 720 \\
\hline
\end{tabular}

\section{Figure 5}

Association of long-term outcomes with angina severity in SIHD patients with and without DM. The primary outcome was defined as a composite of all-cause death, new-onset acute coronary syndrome, non-fatal ischemic stroke, and new-onset heart failure within 2 years. The secondary outcome was defined as a composite of cardiovascular death, new-onset acute coronary syndrome, and new-onset heart failure within 2 years. Abbreviations: CCS, Canadian Cardiovascular Society functional classification; DM, diabetes mellitus. 